\title{
Observations on the breeding habits, shell development, decollation, and reproductive anatomy of Pontophaedusa funiculum (Mousson 1856) (Gastropoda, Pulmonata, Clausiliidae, Phaedusinae)
}

\author{
Barna PÁll-Gergely ${ }^{1} \&$ LÁszló Németh ${ }^{2}$ \\ ${ }^{1}$ Department of General and Applied Ecology, University of Pécs, Ifjúság útja 6, H-7624 Pécs, Hungary, \\ e-mail: pallgergely@freemail.hu \\ ${ }^{2}$ Rekettye u. 24, H-1155 Budapest, Hungary, e-mail: nlmalakologia@tonline.hu
}

\begin{abstract}
PÁll-Gergely B. \& Németh L., 2008: Observations on the breeding habits, shell development, decollation, and reproductive anatomy of Pontophaedusa funiculum (Mousson 1856) (Gastropoda, Pulmonata, Clausiliidae, Phaedusinae). - Malacologica Bohemoslovaca, 7: 11-14. Online serial at <http://mollusca.sav.sk> 8-Feb-2008.

The internal and external egg morphology, shell development, decollation process, mating behaviour and reproductive anatomy (genital structure, inner structure of the penis, fine structure of the retractor muscle and the spermatophore) of the clausiliid Pontophaedusa funiculum (Mousson 1856) are described, and illustrated by photographs of the laid eggs, their inner structure, juvenile, young adult and old individuals, as well as a schematic drawing of the mating. P. funiculum is the only known clausiliid species with hard shelled eggs and the only known example of the family Clausiliidae which mates face to face. The taxonomic position within the Phaedusinae subfamily is mentioned.
\end{abstract}

Key words: Gastropoda, Pulmonata, Clausiliidae, Pontophaedusa, mating, eggs, breeding habits, reproductive anatomy.

\section{Introduction}

Compared to the number of publications addressing taxonomic or ecological problems, only few papers provide information regarding the natural behaviour and habits of clausiliids and, in general, terrestrial molluscs. The paper of PIECHOCKI (1982) is a rare exception.

Pontophaedusa funiculum (Mousson) is distributed along the eastern coast of the Black Sea (LiKhAREv 1962) between Sochi (Russia) and Trabzon (Turkey). The species belongs to the relict Serrulinini tribe of disputed systematic position. It likely belongs to the mainly Asiatic Phaedusinae subfamily (ZILCH 1960, SzeKEREs 1999), but in NordsiecK's view it constitutes a distinct subfamily (Serrulininae) which, nevertheless, is closest related to Pheadusinae (NordSIECK 1999, 2002: 97).

Literature data on this species are mainly restricted to description of shell and genital morphology. According to

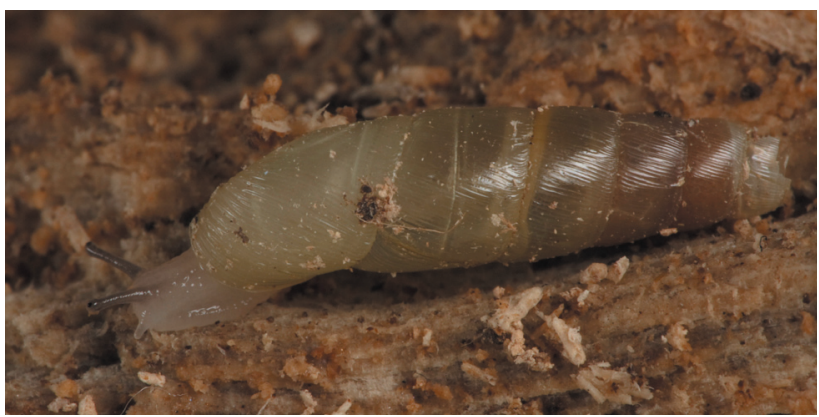

Fig. 1. An adult specimen of Pontophaedusa funiculum. the limited information on biotope preferences (LIKHAREV 1962), this clausiliid of humid forests can be encountered under stones, leaf litter, and fallen, decaying tree trunks. In this paper we describe the observations we made while raising several generations of this snail.

\section{Materials and methods}

This study was prompted by earlier experience of M. SzEKERES and one of the authors (L. NÉMETH) who successfully kept live specimens of $P$. funiculum for several months under room conditions. The breeding experiments described here were initiated with ten adult and two juvenile individuals of $P$. funiculum that were collected by the authors in Turkey, near the confluence of the Morgul and Çoruh rivers at Borçka, in May, 2006.

For our observations the model environment was set up to resemble the conditions of the natural biotope. Initially we used soil, litter and decaying wood material from the original locality, and later on also from similar forest biotopes in Hungary. To ensure high humidity and proper diurnal illumination cycles, the population was maintained in a $100 \times 150 \times 80 \mathrm{~mm}$ translucent plastic box, which was aerated in a regular daily schedule. The snails were fed primarily with carrot, but occasionally also slices of radish, apple or Agaricus ('champignon') mushroom. Ground shells of chicken eggs served as calcium source.

The animals were kept at room temperature under indirect, natural light. The observations were made daily in 
the evenings. Newly laid eggs were moved to a separate plastic box, and then kept under similar circumstances as described above. To determine generation time, separated hatchlings were monitored weekly.

\section{Genital structures}

The genital structure of $P$. funiculum has been published by LikHAREv (1962) and Schileyko (2000), therefore we focus on some additional or insufficiently described details. Fig. 2A shows the genital apparatus of a specimen with four eggs in the lumen of the oviduct. The retractor muscle of the penis, not shown on the drawing of SCHILEYKo (2000), has three branches, each divided in two bundles (Fig. 2D). We found a spermatophore only in one of the dissected specimens. This spermatophore (Fig. 2B) was slim, with a hook-like end in the pedunculus. The inner structure of the penis (Fig. 2C) contains transfer folds in the thicker proximal part. This reticulate part changes immediately into a slimmer, papillate part, in which the rhomboid papillae stand in six lines, and become denser and smaller towards the distal part of the penis.

\section{Description of the behaviour}

Juvenile specimens were often observed licking the fragments of chicken eggs serving as lime source, and were found to spend most of their time on this lime-rich surface as they were attaining adulthood. This behaviour was less common among adults, which were found most frequently on this substrate just before egg-laying.

The growth of the population stopped when the eggs laid by the initial 12 adult specimens resulted in 26 hatchlings. Up to this stage, the snails were kept in a box with 150 $\mathrm{cm}^{2}$ ground surface. But egg laying resumed once the offspring was removed from the box of the adults. Mating was observed only once, but the separated individuals did not lay eggs. This seems to indicate that, at a point, high population density may adversely influence mating behaviour. In this context it is worth mentioning that, unlike in the case of other (smaller) representatives of the tribe Ser-

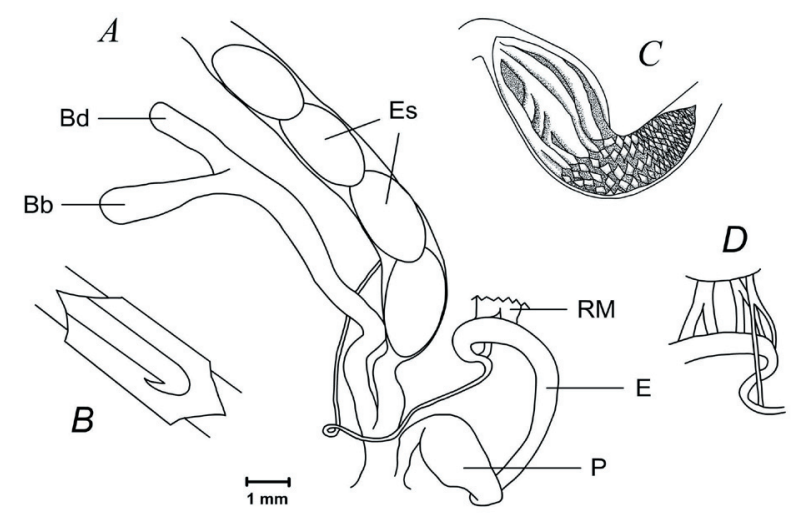

Fig. 2. The reproductive anatomy of $P$. funiculum. The composite scheme shows the male and female genital organs (A), the spermatophore (B), the internal structure of the penis (C) and the fine structure of the retractor penis (D). Abbreviations: bursa of the bursa copulatrix $(\mathrm{Bb})$, diverticulum of the bursa copulatrix $(\mathrm{Bd})$, epiphallus (E), eggs (Es), penis (P), retractor muscle (RM). rulinini (i.e. Pravispira, Dobatia and Serrulina species), under natural conditions it is uncommon to find more than 10 specimens of Pontophaedusa on the same tree trunk.

\section{Mating and development}

During copulation the individuals are face to face to each other (Fig. 3). Members of the Clausiliidae family are known to copulate by "shell-mounting", with no published record of face to face mating (NORDSIECK 2005; K. JoRDAEns, pers. comm.). With very few exceptions, all high-spired snails copulate by shell-mounting (AsAmI et al. 1998).

Following copulation, only one of the mating partners laid eggs. In case of a certain pair, this was always the same individual. This has been observed in the cases of three separated pairs. This indicates sexual asymmetry between the copulation partners, despite their being simultaneous hermaphrodites. According to AsAmI et al. (1998), this kind of asymmetry is common among snails mating by shell mounting, but not those mating face to face.

Five to nine days after the mating ( $\mathrm{n}=3$ pairs), eggs were laid in small cavities of decaying wood or occasionally on litter surface, individually or in groups of two to five, most commonly four. The elongated eggs of

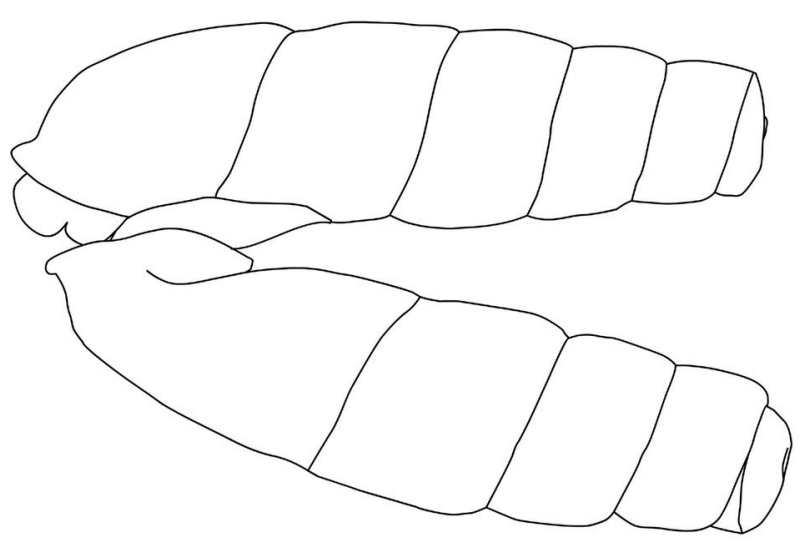

Fig. 3. Face to face mating of $P$. funiculum.

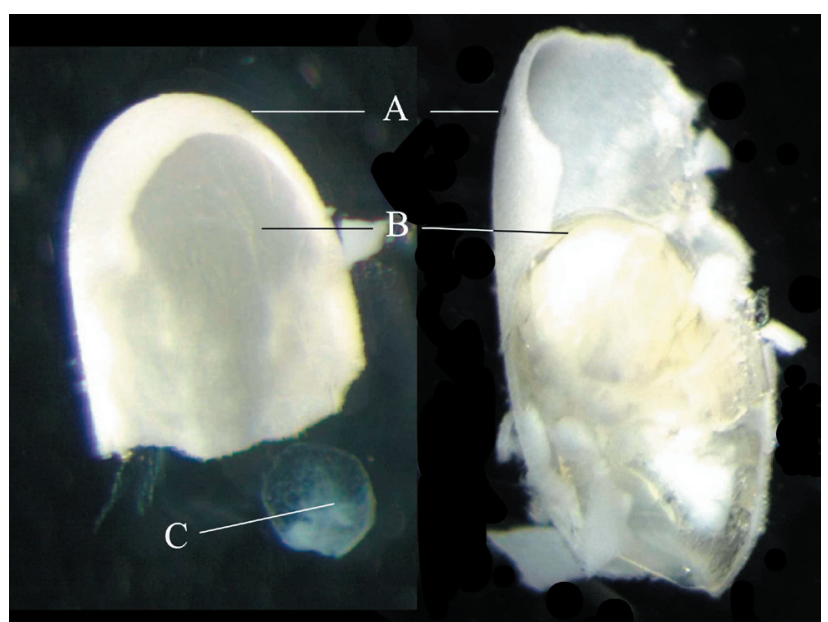

Fig. 4. Inner structure of the eggs. Abbreviations: hard lime-content shell of the eggs (A); opaque sack of the embryo, which is soft immediately after laying (left egg) and fragile, hard after some days (right picture) (B); embryo (C). 
$2.2-2.7 \times 1.0-1.3 \mathrm{~mm}$ are white coloured. Within their limecontaining shell, embryos develop in an opaque sack. Before and at the time of egg laying, this sack is soft, containing jelly-like yolk around the embryo. Later on it solidifies and becomes fragile, and the yolk inside gets condensed (Fig. 4). On one side the sack follows the contour of the egg, whereas on its other side is concave due to the presence of an air bubble between it and the eggshell. It is worth mentioning that, under similar breeding conditions, the eggs of Serrulina serrulata (L. Pfeiffer 1847) and Pravispira semilamellata (Mousson 1863) were found to be spheroid, with soft, jelly-like, lime-free shells (the authors' observation). In young adult Pontophaedusa specimens with translucent shells the eggs were clearly visible. These, up to five at a time, were observed in the last two whorls of the adult individual. Initially the eggs are greyish in the uterus, and then they turn white as the lime-containing eggshells are formed. All eggs of such clusters were laid together (Fig. 6.). The lime-containing eggshells become hard while still in the uterus. Hatchlings appear within 9 to 20 days ( $n=22,14$ at average) from the laying of the eggs. On some occasions, the colour of the eggshell turns brownish before hatching. Upon hatching, young snails emerge from the eggs through an opening that they make by their radula on the eggshell. This process may take up to two days, from the appearance of a little hole on the eggshell till the hatchling's complete emergence from the egg (observation on four occasions). Some eggshells, possibly those with lime deficiency, become distorted during this procedure. Under our conditions, the hatchlings of 2 $\mathrm{mm}$ could reach adulthood, defined by the formation of the adult peristome, within four to five months. Juvenile specimens have only a very thin, almost fully transparent shell which, toward adulthood, becomes thicker and opaque. After reaching adulthood, the shells of the individuals continue thickening, just as in the case of the Albinaria specimens studied by GitTenberger \& Povel (1995). This can be observed on the peristomes and lamellae of the individuals shown in Fig. 5, all having been alive at the time of taking the photographs.

Simultaneously, the light coloured, translucent animals

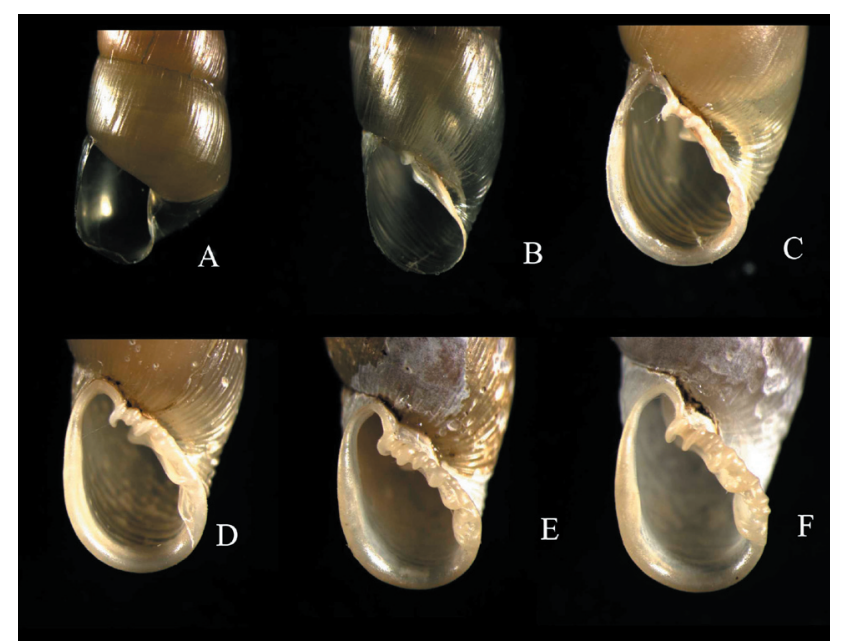

Fig. 5. The peristome is becoming thicker after reaching adulthood. Juveniles (A, B); one year old young snail (C); two years old individual (D); specimens collected in Turkey, their age is unknown (E, F). turn darker upon aging. This is best exemplified by the tentacles, which are initially fully translucent (Fig. 7.), but become black in the adults (Fig. 8). The individuals become fertile at about the same time as their adult peristomes are formed. Soon thereafter they were found to start mating and laying eggs.

Of the 10 adult specimens of $P$. funiculum that we collected in Turkey, only one died during the one and a half year they spent in captivity. This is seen as an indication for the relative longevity of this species. In any case, the shells of the one and a half years old individuals raised in captivity were clearly less eroded than those of their parents collected in Turkey.

\section{Decollation process}

The decollation process of Rumina decollata (Linnaeus, 1758) has been described by HochPöcKLER \& Kothbauer (1975) and КАт (1981). Among clausiliids, decollation has been studied in Albinaria species (GitTenBerger \& Povel 1995).

According to SсHÜтT (2001), non-decollated specimens of $P$. funiculum are very rare in their natural habitats. At the beginning of the decollation process the animal withdraws itself from the apical whorls of the shell, which then become filled with a clear liquid. This retraction starts when the specimens reach a size of 9 to 11 whorls (about at the age of 3 to 4 months). First a septum is formed to separate the apex from the inhabited part of the shell. Subsequently, four to six of the apical whorls break off (in some cases

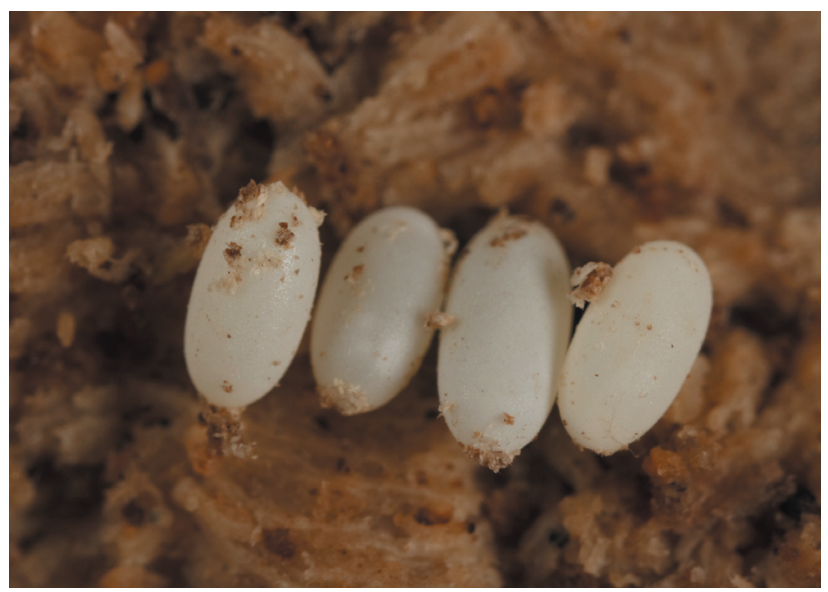

Fig. 6. Eggs are often laid in clusters of four.

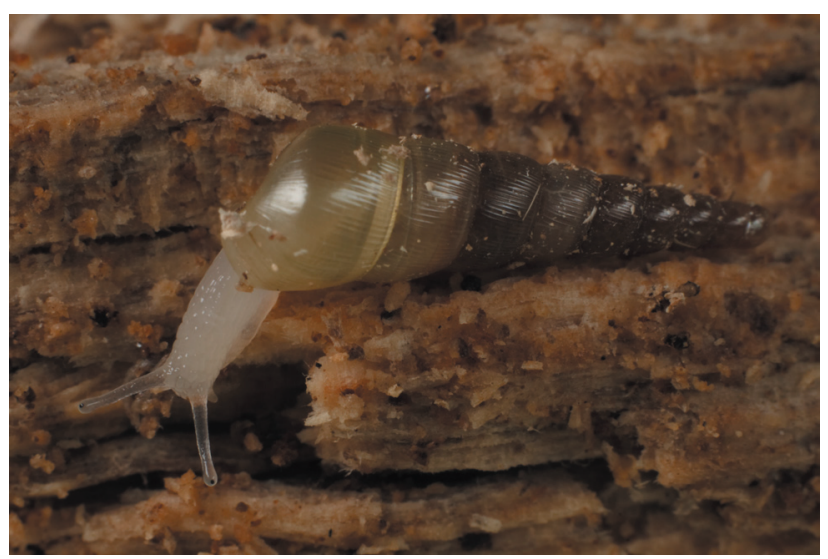

Fig. 7. Juvenile individual with transparent tentacles and glossy, translucent shell. 


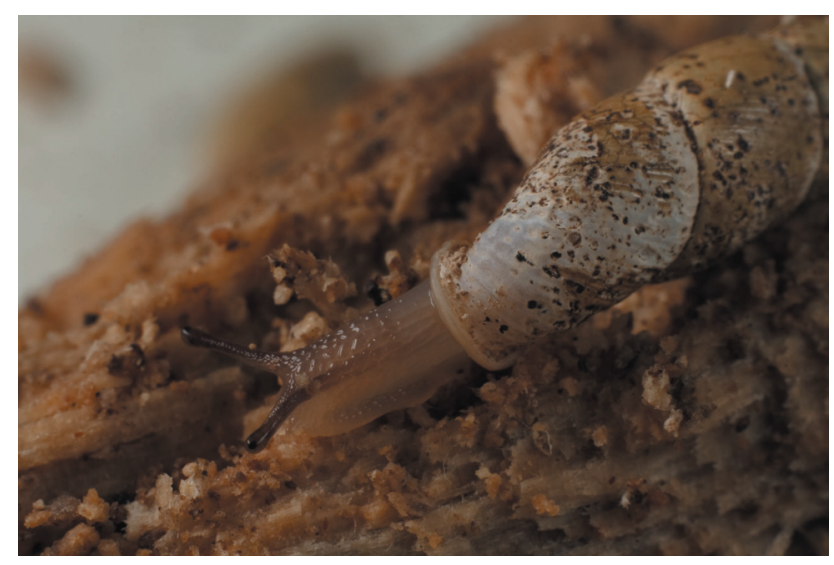

Fig. 8. Old specimen with black tentacles and worn, non-translucent shell.

before completion of the adult peristome), and later on this is followed by gradual fragmentation of any residual shell parts beyond the septum. Unlike in Rumina decollata (Linnaeus 1758), which decollates through a series of septum formation and fragmentation (HOCHPÖCKLER \& KOTHBAUER 1975), in Pontophaedusa only one apical septum is built. Except a few, all of the individuals we raised in captivity became decollated.

\section{Discussion}

The present paper is about the breeding habits, shell-development, life cycle, decollation process and reproductive anatomy of the clausiliid land snail Pontophaedusa funiculum. We made our observations during a whole year, almost every day. The duration of developmental stages in the life cycle are given in Table 1.

In several aspects, this species appears to be quite exceptional among clausiliids. Its eggs with hard, lime-containing eggshell distinguish it from all other known species of this family (ANNA SULIKOWSKA-DrOZD, personal communication). Furthermore, its face to face mating is in contrast to the shell mounting-type copulation of all other clausiliids (Schilthuizen 2003, K. Jordaens, pers. comm.).

Table 1. Time periods in the development of the P. funiculum.

\begin{tabular}{|lll|}
\hline Stages & Duration & Number of observations \\
\hline mating & about 1 hour & 1 pair \\
\hline egg laying after copulation & $5-9$ days & 3 pairs (12 eggs) \\
\hline hatching after mating & $9-20$ days (average: 14 days) & 22 eggs/hatchlings \\
\hline hatching & up to 2 days & 4 eggs/hatchlings \\
\hline start of decollation & about 3-4 months & about 40 \\
\hline reaching adulthood & about 5 months & about 40 \\
\hline lifespan & unknown \\
\hline
\end{tabular}

\section{Acknowledgement}

The authors are thankful to M. SzEKERES for his helpful comments, A. SulikowskA-Drozd and K. JordaEns for providing unpublished information. We are also grateful to B. Horváth for photographing the live individuals and J. Borsics for helping with the digitization of the line drawings.

\section{References}

Asami T., Cowie R. \& Oybahasi K., 1998: Evolution of mirror images by sexually asymmetric mating behavior in hermaphroditic snails. - The American Naturalist, 152: 225-236.

Gittenberger E. \& Povel G.D.E., 1995: Shell growth and decollation in terrestrial gastropods. - Nautilus, 109(1): 38-40.

HochPöCKLer F. \& Kothbauer H., 1975: Der Mechanismus der Dekollation bei Rumina decollata (L.) (Gastropoda: Stylommatophora). - Archiv für Molluskenkunde, 106: 119-121.

Kat P.W., 1981: Shell shape changes in the Gastropoda: shell decollation in Rumina decollata. - Veliger, 24(2): 115-119.

Likharev I.M., 1962: Fauna SSSR, Molljuski, III, 4 (Clausiliidae) [Fauna of the USSR, Mollusks, III, 4 (Clausiliidae)]. - Academic Press, Moscow, Leningrad, 317 pp.

Nordsieck H., 1999: A critical comment on Szekeres' papers concerning Clausiliidae in Basteria 62. - Mitteilungen der Deutschen Malakozoologischen Gesellschaft, 62/63: 23-25.

Nordsieck H., 2002: Annotated check-list of the South East Asian Phedusinae, with the description of new taxa (Gastropoda, Pulmonata, Clausiliidae). - Basteria, 66: 85-100.

Nordsieck H., 2005: Mating biology of Clausiliidae (Gastropoda: Stylommatophora). - Mitteilungen der Deutschen Malakozoologischen Gesellschaft, 73/74: 29-34.

Piechocki A., 1982: Life cycle and breeding biology of Vestia elata (Rossm.) (Gastropoda, Clausiliidae). - Malacologia, 22: 219-223.

SснÜтт H., 2001: Die Türkischen Landschnecken 1758-2000. - Natur \& Wissenschaft, Solingen, 549 pp.

Schileyko A.A., 2000: Treatise on recent terrestrial pulmonate molluscs. Part 5: Clausiliidae. - Ruthenica, Supplement 2, Moscow, pp. 633-634.

Schilthuizen M., 2003: Sexual selection on land snail shell ornamentation: a hypothesis that may explain shell diversity. - BMC Evolutionary Biology, pp. 3-13.

SzeKeres M., 1999: Remarks on Nordsieck's “A critical comment on Szekeres's papers concering Clausiliidae in Basteria 62, 1998”. - Mitteilungen der Deutschen Malakozoologischen Gesellschaft, 64: 17-20.

ZILCH A., 1960: Euthyneura. - In: Gastropoda, Handbuch der Paläozoologie 6., Wenz W. (ed.) Borntraeger, Berlin, pp. 401600, 601-834. 